\title{
À MARGEM DA CAPITAL \\ A gravadora indie Hey, Pachuco! como revitalizadora \\ cultural e social do Barreiro
}

Luiz Alberto Moura ${ }^{1}$

\section{Introdução}

Nossa pesquisa baseia-se no estudo da música à margem do mainstream, ou a indústria convencional, observando-a a partir de um contexto marginal e situando-a sob um prisma de vanguarda, aqui representada pela gravadora Hey, Pachuco!, localizada na Margem Sul do Rio Tejo, em Lisboa, Portugal. Chamada a partir do fim dos anos 1980 de indie, trata-se de uma cultura que emerge dos "subterrâneos" para transformar panoramas musicais e culturais sob a forma de pequenas gravadoras ou selos tendo como princípio dar voz a artistas e bandas que não teriam espaço na grande indústria fonográfica, ou majors. A reação ao status quo e às condições impostas por essas grandes gravadoras fez surgir métodos alternativos de produção musical, baseados em meios e maneiras para o 'escoamento' de produções underground. Noções de autenticidade e de controle são intrínsecas à essa produção fazendo do indie um gênero não só musical, mas comportamental.

\section{Indie enquanto agente de democratização cultural}

As gravadoras indie desnudaram modos de produção 'automatizados' para o consumo 'fácil' e descompromissado, transformando paisagens musical constituindo métodos de democratização da música e, de maneiras singulares, demarcando-se do mainstream. Como atesta Adorno: "Fundamentalmente, a música adquire seu conteúdo de verdade social tão só por meio da oposição, mediante a revogação do seu contrato social" (Adorno, 2011:405). Essas gravadoras ou selos são emblemáticos e essenciais na constituição de novas ideias em relação ao mercado e para o acesso a novos estilos e formas de expressões musicais. Tornam-se centrais para a disseminação da música que acontece 1) nas suas localidades 2) e/ou em outras que possuam bandas ou artistas que se sintam atraídas por aquele movimento. Outrossim, o consumo provocado por esses novos

\footnotetext{
${ }^{1}$ Universidade do Minho, Braga, Portugal. Email: luizalberto.moura@gmail.com ORCID: https://orcid.org/0000-0002-4839-0576
} 
meios de enxergar a música faz com que estas gravadoras assumam papéis de autoridade sobre questões de gosto, de prescrição musical (Gallego Pérez, 2011; Hennion, 2011), passando a ser eixos de democratização através da partilha de informação e de acesso.

As gravadoras indie foram responsáveis pela fragmentação da narrativa única das majors. Isto deu oportunidade para qualquer indivíduo de criar modos próprios de fazer e fomentar a cultura, estabelecer laços sociais através da música e conceber cenas musicais à margem do mainstream. "Essa ruptura abre caminho para a fragmentação da cultura e da sociedade, em que heterogeneidade, multiplicidade, pluralidade, individualidade e fragmentação são os discursos e posições de sujeito proeminentes" (Ulusoy, 2016:246).

Enxergamos então duas vias: uma de resistência e outra de existência. A primeira é uma alternativa a um modo de produção que limita, categoriza, mistifica e só é possível àqueles encaixados nos parâmetros estabelecidos pelas majors. A segunda é uma relação estabelecida na convivência, na liberdade artística e no mútuo apoio.

Os selos indie são canais de expressão artística sob a forma de fonogramas, mas também produzem eventos, reconfigurando o território, criando ou revitalizando lugares para a prática musical, transformando-os em espaços de liberdade e de criatividade. "Minha filosofia era que cada cidade no país deveria ter uma gravadora [indie]" (Bruce Findlay, manager, Bruce's Records, apud Ogg, 2009: 349). Assim, novos meios de lazer e de experiências culturais surgem e, consequentemente, novos mercados e novas maneiras de consumo, democratizando e abrindo o leque de opções musicais. Essas experiências provocam nos seus participantes sensos de pertença ao território, a descoberta de aptidões, a relação com novas tecnologias e a conexão entre eles através do gosto compartilhado, criando identidades.

Segundo Hesmondalgh (1996), este fluxo constante de informação é elemento determinante para que essas movimentações ganhem ritmo, força e sobrevivam, mesmo por períodos determinados. Essas iniciativas só se mantêm através da participação alargada, da produção/captação/democratização de conhecimento. Despontam formas de se relacionar com a música para que indivíduos 'não-capacitados' pela indústria formal possam exercer carreiras (mesmo que não remuneradas) dentro dessas comunidades. "Há algo na música que nos incita a criar uma conexão com algum contexto maior, com algo que vá além do pedaço de plástico no qual ela veio" (Byrne, 2014: 209). No indie, a cultura não é um produto de dominação, mas um caminho para uma sociedade mais diversa, com o acesso à arte de todos e para todos. O comprometimento dentro desses campos, ou cenas, permite a constituição de redes de afetos e o empoderamento de 
pessoas previamente 'não-qualificadas' para a criação novos mercados. Para isso foram importantes a curiosidade, o estar junto, e a experimentação (Murphy, 2015).

Foi assim com os Buzzcocks, banda de Manchester, pedra fundamental deste movimento ao registrar (em dezembro de 1976), produzir e lançar em janeiro de 1977 o EP Spiral Scratch com recursos próprios, ou seja, sem o apoio de uma grande gravadora. Para tal, a banda juntamente com seu manager, Richard Boom, fundaram um selo, New Hormones, e, assim, mostraram ao mundo que era possível um meio de produção que pudesse estar sob total controle do $\operatorname{artista}^{2}$. E tão importante quanto isso foi dividir $o$ conhecimento $^{3}$ (Dale, 2009; Moura et al,, 2020). O saber, o modus operandi não seriam mais propriedade das grandes corporações. Qualquer pessoa poderia montar um selo e divulgar os projetos musicais dos amigos, da rua, do bairro, da cidade etc.

\begin{abstract}
“A desmistificação foi importante. E foi aí que a política entrou realmente - o compartilhamento de conhecimento. E o encorajamento de quem tenta empreender em qualquer tipo de campo artístico para tentar seguir seu próprio caminho e fazer as coisas por conta própria, sem precisar de permissão - todas essas coisas eram muito importantes e empoderadoras" (Geoff Travis, manager, Rough Trade, apud Ogg, 2009: 192).
\end{abstract}

Impulsionados pela iniciativa dos Buzzcocks, selos indie começam a se espalhar pelo Reino Unido a partir do fim dos anos 1970, com a 'missão' de agrupar artistas e bandas 'indesejados' pelas grandes corporações. Com isso, floresce o engajamento nessas coletividades. "Quando algo é tão pequeno e tão underground, envolve todo mundo - não somente os donos das lojas de discos, mas os dos clubes, as revistas, as bandas. É do interesse de todos colaborar" (Jeff Nelson, manager, Dischord Records, apud Azerrad, 2001: 144). Tal atitude, inspirada pelo ethos punk, mas também por ideias que remontavam a contracultura dos anos 1960, foi vital para a quebra dos padrões estabelecidos para a produção musical. Segundo Hesmondalgh "produtos culturais podem encorajar uma atitude crítica em relação às condições sociais e artísticas e podem iniciar ações em resposta a essas condições" (Hesmondhalgh, 1996: 14).

\footnotetext{
${ }^{2}$ A banda lisboeta Croix-Sainte chegou - a exemplo do Buzzcocks - a criar um selo, a Alliance Records, para lançar o disco The Life of He, de 1985. Retirado de https://www.discogs.com/ artist/190588-Croix-Sainte

${ }^{3}$ Spiral Scratch teve efeito imediato no meio. Um deles foi o disco 'Smokescreen' da banda The Desperate Bicycles, também considerado seminal no que se refere à desmistificação e consequente democratização do acesso aos meios de produção musical. Ou como dizia na contracapa do segundo single da banda, 'The Medium was Tedium', de 1977: "Foi fácil, foi barato, vá e faça". Na mesma época, outra banda, o Scritti Politti, detalharia os custos de produção na contracapa do single 'Skank Bloc Bologna' (1978) (King, 2012; Ogg, 2009).
} 
Logo, enxergamos no indie práticas de inclusão. Por um lado vê-se um movimento de renegar o que é popular, de ser um 'guardião da boa música' (Hibbett, 2005; King, 2012); do outro, promover o acesso à produção musical a todos, fazer da música algo próximo de qualquer pessoa. Gravadoras indie se demarcam das majors por permitir que o leque de opções musicais seja mais amplo. Geram afeto e fãs fiéis e inserem-se em ou desenvolvem comunidades em torno da música. O papel é de disseminar o acesso à música. Seja através da prática, ou seja, promovendo locais, combatendo a precariedade e fazendo com que artistas e bandas possam se expressar, seja na forma da produção, dando a oportunidade desses autores de divulgarem sua música na forma de fonogramas (físicos ou virtuais). Em ambas, a gravadora indie tem papel fundamental. Ela estará nas 'duas pontas' do processo, fomentando cenas e divulgando novos nomes (Guerra, 2017b).

\section{O indie em Portugal}

Em Portugal, assim como no resto do mundo, o que ditou essa revolução na música foram 1) a influência direta dos selos indie do Reino Unido 2) mas também a necessidade econômica, pois não havia gravadoras o suficiente e as que existiam não estavam dispostas, a partir de 1982, a investir em artistas sem retorno 'certo'. Isto impulsionou aqui um esquema de "autogerenciamento, na organização de novos próprios espaços para a promoção de uma música própria” (Tosh Ryan, manager, Rabid Records, apud Ogg, 2009: 298); 3) e a necessidade de fazer frente à dominação cultural do eixo Lisboa-Porto e, mesmo dentro dessas cidades, promover posturas anti-establishment.

Depois de 40 anos de ditadura salazarista ${ }^{4}$, a partir de 1974, a abertura política funcionou, como diz Guerra (2018), como pano de fundo para mudanças profundas na cultura e na forma como os jovens portugueses encarariam o lazer e a criação artística a partir dali. Novas identidades eram constituídas pelas possibilidades abertas pela disseminação do punk rock em um rompimento com padrões de consumo e sociabilidades a partir da apresentação de uma nova música à juventude local combinada com modos de ser, de vestir e de se portar.

Porém, nos anos 1980, notadamente a partir de 1982, devido a uma crise econômica, o espaço para novas bandas fora dos padrões do mainstream rareava. Logo, era necessário cria-lo. As primeiras gravadoras indie portuguesas como Fundação

\footnotetext{
${ }^{4}$ Para mais ver https://www.dn.pt/edicao-do-dia/15-fev-2020/salazar-o-ditador-11821147.html. Acessado em 30/08/2021.
} 
Atlântica ${ }^{5}$, Dansa do Som ${ }^{6}$, Ama Romanta ${ }^{7}$, Facadas na Noite ${ }^{8}$, entre outras, tiveram o papel de fomentar e gerir novas movimentações a fim de tornar a música portuguesa mais plural, mais democrática.

Assim, o indie proporcionou uma nova divisão do mapa musical português em que centros menores também passariam a ter voz através da produção musical e cultural própria, autocentrada, independente e mais autossustentável (majoritariamente a partir dos anos 2000). Com a proliferação de selos indie, foi ganhando força a ideia de que não era mais necessário estar em Lisboa ou no Porto para produzir música. Se a dependência econômica da capital era inevitável num primeiro momento (por questões de distribuição), seria possível existir artisticamente à margem dela.

\footnotetext{
“[H]á que relevar que o circuito independente das editoras é essencial para um equilíbrio no campo musical, na medida em que dão lugar a novos valores musicais de dimensão ainda experimental e underground, bem como a importância de uma aposta em estruturas de médio alcance" (Guerra, 2010: 538).
}

Assim, localidades menores acabaram por desenvolver sonoridades originais e destacadas da capital, como Braga, Coimbra, Caldas da Rainha, entre outras. Como o Barreiro, tão próxima da capital e um dos grandes centros industriais do país do século passado (Faria e Mendes, cord., 2010) e, ao mesmo tempo, querendo carente de uma cultura musical e de eventos própria. Neste caso, a Hey, Pachuco! se valeu de uma postura mais moderna e menos romântica vista nos selos indie a partir dos anos 2000, para ter uma existência sustentável e sem renunciar aos princípios que 'regem' o gênero. Isto só é possível a esses selos quando se tornam mais profissionais e combinam outros modelos de negócios a edição de discos, como eventos, feiras, licenciamento de artistas ou mostras ${ }^{9}$, entre outros.

Nestes processos de profissionalização, um dos pontos que diferem às gravadoras indie das majors são os managers destes selos. São mavericks (King, 2012), notáveis (Guerra, 2010) ou inovadores, figuras imprescindíveis para a democratização de atividades culturais em seus territórios. São responsáveis diretos pela apresentação de novos estilos e gêneros para outros indivíduos, repartem informação, ajudam a criar e

\footnotetext{
${ }^{5}$ https://www.discogs.com/label/44159-Funda\%C3\%A7\%C3\%A3o-Atl\%C3\%A2ntica

${ }^{6} \mathrm{https}: / / \mathrm{www}$.discogs.com/label/21400-Dansa-Do-Som

${ }^{7} \mathrm{https}: / / \mathrm{www} \cdot$ discogs.com/label/21399-Ama-Romanta

${ }^{8} \mathrm{https} / / /$ www.discogs.com/label/119340-Facadas-Na-Noite

${ }^{9}$ Como o ECO - Mostra de Música do Barreiro, realizada pela Hey, Pachuco!
} 
fomentar cenas transformando consumidores em produtores e vice-versa. Estes notáveis são impulsionadores da crença de que é possível existir um mercado mais justo em que diversas formas de música sejam acessíveis e não só as impostas pelo mainstream e a indústria fonográfica. Esses mavericks, ou prescritores, são, como diz Guerra (2013), propagadores, educadores, fazendo o papel de polinizadores culturais, determinantes nos processos de disseminação e de fundamentação da música em suas localidades.

Esses cenários de evangelização, de difusão, geram exatamente a descentralização (Hesmondhalgh, 1996, 1998). Se ela começa nos meios de produção passa também pela forma de usar território, o que faz muito sentido quando falamos de países com mercados fonográficos reduzidos como Portugal. Se um atrelamento a Lisboa e ao Porto se fez ou ainda se faz necessário por motivos econômicos, por serem os principais e únicos polos do país, a descentralização desse eixo mostra-se fundamental por motivos artísticos e estéticos, pela 'não padronização'. Se o indie é um estilo, ou gênero, que reconfigura influências externas e as retrabalha internamente para depois ser um meio de expressão de determinados grupos ou nichos, as características do local têm importância crucial ao falarmos em novas formas de expressões musicais. Ou seja, uma cidade/região/bairro etc. recebe a informação exterior, a processa e o resultado torna-se 'marca' identitária musical do lugar (Costa e Guerra 2016; Guerra e Moura, 2016; Janotti Júnior e Pires 2018; Oliveira, Costa, e Guerra 2015).

O local é onde a prática musical o leva a interagir com outros fãs, estabelecer relações de amizades, onde ideias surgem, projetos são criados e artistas são descobertos. O território ganha status simbólico para uma cena, podendo ser, para Becker (apud Bennett \& Peterson, 2004), uma cidade, um bar ou um clube. Os lugares são, como diz Crossley (2015), 'foci' para novas redes de contatos pois atraem fãs de um mesmo tipo de música ou interessados em descobrir novas sonoridades.

\section{Indie enquanto Mundo da Arte}

Com a revolução em curso após a popularização da internet em meados dos anos 1990 e as novas tecnologias de gravação e distribuição musical, as práticas do-ityourself $^{10}$ (faça você mesmo, ou DIY) e do do-it-together (façamos juntos, ou DIT), se

\footnotetext{
${ }^{10}$ Sob um olhar etimológico, o conceito de 'do-it-yourself' era ligado às questões de pequenos consertos ou reformas caseiras, reparos feitos sem a supervisão ou por um especialista. Com o tempo abrangeu uma série de práticas culturais criativas, incluindo música (Bennett, 2018a: 133).
} 
expandem e a democratização se torna mais possível. "A ética DIY nas décadas de 1980 e 1990 buscava a democratização da produção musical, no sentido de que se baseava em valores de acesso e participação, cooperação e colaboração" (Tarassi, 2011: 88-89). As novas formas de produção, de distribuição e de promoção da música geradas pela internet e pelo barateamento e consequente popularização de softwares constituem novos modos de participação destes indivíduos no meio artístico, democratizando a música nos dois sentidos. De quem a faz e de quem a dissemina (muitas vezes, são as mesmas pessoas).

Mas para serem criadores, os sujeitos ligados à gravadoras indie, devido à uma condição inicial sem recursos em que geralmente se encontram, precisam criar mecanismos de sobrevivência e ajuda interna. Quem circunda um selo indie tem a consciência de que seus papéis (mais de um, pré-estabelecidos ou não) são vitais (porém, nem sempre organizados) a fim de manter fluxos de trabalho ágeis, vanguardistas e pouco dispendiosos. Gravadoras indie são como 'sociedades cooperativas' (Maffesoli, 2014), compostas por pessoas conectadas por 'acordos' não escritos (GUERRA, 2010, 2013) em que, como diz Maffesoli, o afeto será o cimento que as une e "em que as solidariedades se enraízam numa repartição que devolve todo seu sentido a todos os aspectos da natureza humana" (Maffesoli, 2014: Kindle).

Logo, mesmo dentro de métodos menos 'românticos' ainda emerge (e é um dos grandes diferenciais do indie) a necessidade de estar junto e, importante, o fazer junto. A empatia, para usar um termo frequentemente colocado por Maffesoli (1998), está e precisa estar na 'ordem do dia' nessas comunidades. O social 'racionalizado' dá espaço a uma socialidade com uma preponderância para a identificação entre seus participantes (Maffesoli, 1998). "O underground (...) é, em essência, um trabalho criativo coletivo (...) que expressa a estética cotidiana em contextos da cultura jovem" (Guerra, 2017b: 288).

Com isso, rumamos ao conceito de mundos da arte de Howard Becker (1982). Para um art world existir, Becker diz que é preciso haver "um conjunto de pessoas cujas atividades são necessárias para a produção dos trabalhos que aquele mundo, e talvez também outros, definem como arte" (Becker, 1982: 34). A arte, enquanto ação coletiva, é produtora de práticas, desenvolve o conhecimento e o compartilhamento de saber; levanta problemáticas e reflexões sobre a realidade de localidades e faz esses coletivos agirem em torno delas e para elas (Guerra, 2019b). A produção musical em grupo, em comunidade, reveste a música de significados que serão percebidos, no caso do indie, por quem estiver dotado do poder de decifrar esses signos (Martins, 1997, 2004; Novak e 
Brandt 2018; Santaella, 1995) E o indie enquanto forma de expressão de um território trata-se de:

[...] representações cognitivas e referenciações afetivas do espaço local enquanto território de práticas quotidianas, palco de existência corrente, cenário de familiaridade, fonte de recursos tácticos, sede de estratégias sociais, referência de episódios vividos ou narrados, lugar de experiências partilhadas e de sentimentos de pertença. (Costa, 2008: 47).

Se Becker (2007) disse que a arte é uma forma de "contar algo sobre a sociedade", então tomando o indie como arte podemos enxerga-lo como ele representa essa sociedade (ou micro sociedades) a partir dos modos de produção. Como o autor diz, o contexto em que a arte é criada é importante para a entendemos. Isto se traduz na condição, no ambiente do trabalho em comunidade e a partir do DIY e do DIT, na resistência ao status quo, à precariedade, à falta de recursos e principalmente na democratização da música e dos meios de produção musical.

Segundo Oliveira et at:

[...] esses circuitos $D I Y$ são uma forma muito eficiente de afirmar as especificidades da diferença (estética, artística, simbólica, processual ou outra) que é explorada como uma vantagem competitiva econômica na estruturação dos mercados para os bens e serviços que são produzidos por esses criadores. Estes circuitos são uma forma de afirmação e exploração de oportunidades de negócios, ligadas a determinados nichos de mercado, baseados na diferenciação e distinção (nos bens e serviços, na forma como são vivenciados, na distinção simbólica que o seu consumo veicula, etc.), e nas aproveitar sua maior propensão ao risco (em comparação com atividades e jogadores convencionais - ver Caves, 2002) enraizada em sua capacidade de operar seu conhecimento específico e gerenciar sua reputação. (Olveira et al, 2016:803).

Sendo um fenômeno global e local (Guerra, 2018), o indie, através do DIY, nos ajuda a entender os processos pelos quais ele é reconfigurado a partir de características de particulares e de indivíduos. O DIY foi como a divisão do átomo, uma cisão que permitiu a liberdade. (Reynolds, 2009). Foi a reação à falta de oportunidades, ao desemprego, tédio, ao "materialismo ganancioso, a negação de prazeres alternativos, privação social geral e alienação" (McKay, 1998: 19). De acordo com Guerra:

[...] o DIY é um poderoso criador de semântica e uma forte rubrica que suporta a compreensão de uma vasta gama de gêneros, formas expressivas, modos de produção, exibições afetivas e estéticas, traços autorais e estilísticos. (Guerra 2017a: 295).

Através dessas éticas, o empoderamento de indivíduos nos processos de produção cultural (McKay, 1998) como uma alternativa ao mainstream geram o que Oliveira et al 
(2016) chamam de contaminação entre os diversos setores artísticos de localidades tornando as fronteiras entre o profissional e o amador cada vez mais embaçadas. Levam os amadores (no sentido stricto do termo) em direção aos métodos mais profissionais sem abandonar à ideologia que os faz diferentes do status quo. A atividade se torna especializada, calcada em sentidos de pertença a uma comunidade (seja um território ou por uma partilha de gosto), com forte networking e relações sociais (Oliveira et al, 2016).

\begin{abstract}
As características do DIY (determinação, realização, liberdade e ação coletiva), lógicas e procedimentos permitem que esses músicos e promotores culturais criem e promovam o que querem e o que pensam ser importante para a cena cultural da cidade. Em outras palavras, as habilidades do DIY, as lógicas e os procedimentos podem ser vistos como uma ferramenta de empoderamento e autonomia, como maneiras de trabalhar de forma independente em relação aos padrões e hierarquias estabelecidos, assumindo o controle de todo o processo. (Oliveira et al, 2016: 796).
\end{abstract}

São ambientes de viés cultural que tendem a se esvair se não houver um suporte, um núcleo que dissemine e prescreva essa produção musical que são, neste caso, gravadoras indie. E estas se 'cercam' de outros agentes como produtores, casas de shows, bares, lojas de discos, fanzines, rádios livres etc., provendo conteúdo e gerando interações para que uma cena possa florescer ${ }^{11}$ (Andersen \& Jenkins, 2015: 144).

Para Hesmondalgh:

[...] [a]s pessoas trabalham melhor onde há um grau mínimo de controle hierárquico e onde há altos níveis de igualdade de responsabilidade, oportunidade e recompensa. Um ideal é a colaboração com igualdade genuína. Isso nunca é alcançado na prática, em uma sociedade crivada de classes, gênero e divisões étnicas, mas quanto mais os momentos particulares se aproximam desse ideal, mais bem-sucedidos considero em termos de democratização, em igualdade de condições. (Hesmondalgh, 1996: 16).

Esses 'mundos da arte' são definidos por Crossley como “espaços sociais e físicos, de interação e de valores, símbolos, definições objetos compartilhados e práticas geradas através do tempo e por essas interações" (Crossley, 2015: 29). Eles, segundo o autor, são criados quando interesses em comum e convívios ganham forma. Além disso, geram o que Crossley (2015) chama de bens internos (ou capital simbólico) que possuem valência dentro deste mundo, mas não fora dele ${ }^{12}$ (cf Bourdieu, 1993). O trabalho em conjunto, o

\footnotetext{
${ }^{11}$ Lojas de discos eram (e ainda são em certo grau) primordiais para o que Reynolds chama de 'nó' em uma comunidade musical. Em cada cidade com uma cultura musical avultada, o autor destaca que geralmente existe um estabelecimento do tipo que serve para encontros e para a educação musical (2009).

${ }^{12}$ A propósito desta última afirmação, a profissionalização do indie, como veremos adiante, praticada com mais fluidez na última década por uma boa parte das novas gravadoras do gênero, procura fazer desses
} 
do-it-together, dá a este campo (Bourdieu, 1993) capital simbólico que se reflete em reputação, prestígio e o status de serem produtores da 'boa música'.

A colaboração numa rede que inclui associações culturais, distribuidoras, espaços para concertos, fanzines e imprensa de nicho, e promotoras resulta numa relação simbiótica e sinergética entre vários agentes, onde verificamos o mesmo tipo de cooperação proposto por Becker no seu estudo aprofundado sobre os mundos artísticos. (Belchior Nunes, 2018: 34).

Diane Crane (1992) avança com os conceitos de Becker ao falar em redes sociais informais, noção, como diz Guerra (2010), mais diversificada. Estas redes oferecem recursos para a produção, disseminação e expressão destes trabalhos (idem).

Esta combinação parece ser estimulante para a produção de cultura que é esteticamente original, ideologicamente provocadora ou ambas. Isto porque estas redes tendem a atrair os jovens, trazendo inovação, e porque se sustentam num feedback contínuo entre os criadores e entre estes e as audiências. (Guerra, 2010: 499).

A ideia de Crane se mostra proveitosa quando a autora discorre como essas small cultural organizations (idem, 1992) são porosas à inovação, seja tanto em termos musicais quanto estéticos e procedimentais, e como são próximas às suas audiências, sendo sensíveis a elas e permeáveis as novas tecnologias. Elas combinam, segundo Crane, a necessidade preencher lacunas de gostos pessoais democratizando estilos musicais, dinamizando valores alternativos ao mainstream e promovendo sociabilidades em torno de um novo - ou de novos - tipo(s) de (fazer) música (Crane, 1992). Para ela, "é impossível entender a natureza e o papel da cultura registada na sociedade contemporânea sem examinar as características das organizações em que é produzida e disseminada" (Crane, 1992: 4).

\section{Cenas musicais e o indie}

Ao analisamos cenas musicais em Portugal, percebemos a presença de atores transformadores que vão ao encontro daquilo que Bennett e Peterson discorrem sobre movimentações musicais formadas por práticas coletivas em um "espaço delimitado" e que, durante um período, sujeitos são modificadores do território usando a música, afetos

'bens' ou 'valores' algo que também possam ser compartilhados com o grande público, como forma de sair de uma 'marginalidade', de ser um elemento de prescrição musical e de aumentar ganhos. 
e traços culturais como ferramenta de sociabilidades, rebatizando influências externas como próprias do lugar criando as cenas musicais (Bennett \& Peterson, 2004: 8). O vocábulo 'cena'13, segundo Bennett \& Peterson (2004), começou a ser utilizado por jornalistas a partir dos anos 1940 para expressar o que acontecia no mundo "marginal e boêmio" do jazz americano. Ainda hoje é empregado para coletividades que possuem distinções culturais e autoconsciência necessárias para se destacarem (Thornton apud Bennett \& Peterson, 2004). Mas, mesmo que este conceito ainda seja volátil e passível de diversas interpretações é o que se insere mais claramente nas peculiaridades das coletividades por nós pesquisadas. Bennett \& Peterson (2004) o expandem, inicialmente discutido por Will Straw,(1991), para três tipos de cenas, já amplamente discutidos por diversos autores (Cohen, 1991, 2007, 2012b; Guerra, 2010, 2013; Janotti Júnior \& Pires, 2018; Kruse, 1993, 2010; Shank, 1994): as cenas locais, translocais e virtuais.

\begin{abstract}
O primeiro, a cena local, corresponde mais próximo à noção original de uma cena agrupada em torno de um foco geográfico específico. O segundo, a cena translocal, refere-se a cenas locais amplamente dispersas, moldadas em uma comunicação regular em torno de uma forma distinta de música e estilo de vida. O terceiro, a cena virtual, é uma formação emergente em que pessoas espalhadas por grandes espaços físicos criam o senso de cena por meio de fanzines e, cada vez mais, pela Internet. (Bennett \& Peterson, 2004: 6-7).
\end{abstract}

Festivais, importantes modelos de negócios que se tornaram fulcrais para a sobrevivência de várias gravadoras portuguesas, seriam, de acordo com Bennett e Peterson (2004: 9) especificidades de cenas translocais. São eventos em que milhares de pessoas se reúnem em locais e em momentos específicos para celebrar a música e trocar experiências (Krueger, 2019).

No caso de gravadoras como a Hey, Pachuco!, festivais como o Barreiro Rocks ${ }^{14}$ mais que identificarem uma cena translocal, são fontes de renda, de divulgação de novos artistas, de interação e são também modelos de como os selos indie precisaram alargar as fronteiras para expandir os negócios, como visto nas últimas duas décadas (Moura et al, 2020). As gravadoras indie portugueses promovem uma 'economia de aglomeração', ou

\footnotetext{
${ }^{13}$ Antes, no que se refere ao uso de termos, 'cena' (BENNETT, 2004, 2018b; BENNETT; PETERSON, 2004; COHEN, 1991, 2007, 2012b; KRUSE, 2010), 'subcultura' (HEBDIGE, 2018), 'tribos' (MAFFESOLI, 1998), e etc., optaremos pelo uso do primeiro por considerarmos mais adequado às necessidades dos fenômenos aqui representados e estudados.

${ }^{14}$ Criado em 2000 e inicialmente chamado de Pachuco Fest, o Barreiro Rocks foi dos festivais mais emblemáticos e conectados com o território em Portugal nos últimos 20 anos. Foi encerrado em 2019 (Morais, 2015)
} 
seja, geraram efeitos positivos pela proximidade de serviços ligados à música em suas localidades, fomentando criatividade e produtividade (Krueger, 2019: 269).

Na questão do indie português, esses festivais impactam direta e positivamente na economia regional por alguns dias ao ano. Há a celebração do local, da comunidade em torno de uma cena que valoriza e descentraliza a música. Assim, atesta Stahl (Finch, 2015), quando diz que cenas podem ser vistas geralmente como sinais de vitalidade urbana e cultural de uma localidade na sua vida social, um reflexo da trajetória dos sujeitos enquanto 'cidadãos' e produtores de cultura. Nestas relações, o "lugar e o peso de uma empresa no campo são definidos na relação com todos os outros agentes do mesmo espaço económico" (Abreu, 2010: 14).

Estudar estes tipos de relações nas comunidades e os territórios onde, neste casos, são formados os selos indie é, segundo Firmino da Costa, "estudar aquela forma musical procurando compreendê-la enquadrada na configuração cultural e no tecido social" (Costa, 2008: 3). O território é visto não só como produtor de cultura, de música, mas de afetos, de comunidades, de forças de trabalho cooperativas e de amizades. "A produção do espaço depende de seu reconhecimento como um 'lugar de pertencimento'“ (Janotti Júnior \& Pires, 2018: 146), uma vez que as cenas musicais fundem as características artísticas dos seus participantes com as do território. Em outros casos, algumas coletividades renegam particularidades locais como forma de movimento de resistência, de desagravo, reescrevendo o ambiente à margem do status quo. Cenas, enquanto campos (Bourdieu, 1993, 1996), não estão livres de conflitos internos. Porém, cenas nascem também como respostas ao que (LeGates \& Stout, 2011) definem como relações numa grande cidade geralmente são: impessoais, superficiais e transitórias.

A precarização e a informalidade ${ }^{15}$ também são outras características marcantes de cenas que procuram ser combatidas com posturas cada vez mais profissionais, como dissemos, e não mais de rejeição à grandes empresas e ao poder público, mas de diálogo. O que se observa em casos como o da Hey, Pachuco!, são parcerias com governos locais para práticas de reordenação do território através de festivais, programas sociais, revitalização de espaços, entre outros, como também como forma de marketing dessas áreas. Com isso, as gravadoras conseguem a cedência, por parte dos poderes, de espaços e recursos (ainda que escassos). Essas práticas revelam descontentamento com políticas locais de acesso e disseminação da música, propondo novas soluções.

\footnotetext{
${ }^{15} \mathrm{Na}$ luta contra a precariedade e a falta de espaços para a prática musical restaurantes, pequenos bares e demais locais podem hospedar música ao vivo e, portanto, podem fazer parte de uma cena
} 


\begin{abstract}
As cidades apoiam-se cada vez mais na sociedade do conhecimento no tocante a um leque diversificado de actividades: informação, ciência, tecnologia, lazer, linguagens e criação. Neste sentido, a cultura não se limita a uma oferta de fruição desinteressada, abarca uma rede de actividades económicas, é factor de afirmação competitiva e de atracção de recursos, de investimentos e de pessoas, mantendo o seu papel de comemoração ritual e festiva de comunidades e de integração simbólica e lúdica da população, assumindo importantes efeitos na coesão dos tecidos sociais. (Guerra, 2010: 302).
\end{abstract}

Segundo Sara Cohen, esses locais também são vitais para identidade do território enquanto produtor de música. Eles "surgem através de práticas musicais regulares, rotineiras e colaborativas, bem como através de memórias individuais e coletivas, histórias e imaginações de músicos" (Cohen, 2012a: 169). Esses lugares ficam marcados na memória coletiva relacionadas a experiências do passado e à associação a sonoridades e gêneros (idem: 140).

Mas não podemos nos esquecer de que, apesar de todos o ethos, a ideologia e o desejo pelo novo, pela disseminação de uma música que não fosse àquela veiculada pelo mainstream, as gravadoras indie são negócios, criadas dentro de mercados regidos por óticas capitalistas de consumo. Portanto, precisam da venda, do lucro para sobreviver, mesmo que a arte seja o norte inicial a ser seguido. Quando Belchior Nunes diz que "[O] capital económico é deixado em segundo plano face à preponderância do capital simbólico (informal)" (Belchior Nunes, 2018: 32), temos que aqui fazer a ressalva de que, mais uma vez, uma gravadora indie é um empreendimento. O que as difere em geral é o tratamento mais humano e mais artístico com o seu 'produto': os artistas, os discos, singles, cassetes etc., além claro do modo de produção. O capital simbólico (Bourdieu, 1993) é o que lhes confere valor e as distingue em relação às majors. O papel das indie é primordialmente agir como:

[...] agentes propulsores de inovação e criatividade dentro da indústria, ao mesmo que abrem o leque de estilos musicais disponíveis para o público consumidor de música, fazendo chegar-lhe um número inestimável de artistas que nunca seriam contratados em primeira instância pelas editoras multinacionais. (Belchior Nunes, 2018: 30).

\title{
Uma gravadora à margem da (do) Capital
}

No dia 30 de setembro de 2000, nascia o conceito para duas novas ideias para revitalizar a cena cultural então quase inexistente no Barreiro, cidade localizada na 
margem sul do Rio Tejo, pouco mais de sete quilômetros de Lisboa. A gravadora Hey, Pachuco! ${ }^{16}$ e o festival Barreiro Rocks eram criados para 1) absorver a produção musical que havia na localidade; 2) fazer escoar sob a forma de fonogramas e concertos esta produção 3) promover o intercâmbio entre bandas de outras cidades fazendo o Barreiro ser conhecido por uma movimentação musical. $\mathrm{O}$ artífice daquelas novas atividades era Carlos Ramos ${ }^{17}$, músico barreirense e a época integrante da banda local Act-Ups. "O propósito inicial [de criar o festival e a gravadora] teve a ver com a falta de acesso a eventos culturais no Barreiro. Tudo foi feito com base no do-it-yourself, sem verbas, com a ajuda da comunidade" (Carlos Ramos, músico, em entrevista pessoal).

No verão de 2000, Carlos montara o estúdio King em casa, pequeno, com um computador pessoal e começou a registrar bandas do Barreiro informalmente como The Ballyhoos e Dynamic Duel. Ao mesmo tempo, outra banda local, The Sullens possuía também um EP gravado pronto para ser lançado. De uma só vez, havia três registros feitos no Barreiro e sem uma via para que pudessem ser distribuídos sob a forma de fonogramas. Para a promoção dos álbuns (que seriam lançados sob a forma de CDRs, CD regraváveis de forma caseira) ${ }^{18}$, surgiu a ideia de criar uma gravadora e não só um concerto de lançamento, mas um festival com as três bandas mencionadas e outras, como forma de integrar e promover a troca com artistas de outras regiões. Assim surgia ao mesmo tempo um selo e o Pachuco Fest que em 2002 mudou o nome para Barreiro Rock por sugestão da câmara municipal local, que considerava mais atrativo ter o nome da localidade no festival, para assim garantir o apoio necessário para a realização do evento.

Tínhamos três discos para lançar naquele verão e não sabíamos o que fazer com eles. Sabíamos que aquele tipo de música não ia interessar às grandes gravadoras e então resolvemos agregar aqueles discos sob um mesmo símbolo e nome e assim surgiu a Hey, Pachuco!. De repente tínhamos uma gravadora. (Carlos Ramos, músico, em entrevista pessoal).

A Hey, Pachuco! nasceu sob a premissa do modelo de negócio que marcaria as gravadoras indie do início do novo século. Com a popularização da internet e a explosão da troca gratuita de arquivos musicais via $\mathrm{mp} 3^{19}$, Carlos percebeu que somente a venda

\footnotetext{
${ }^{16}$ http://heypachuco.pt/. Acessado em 17/09/2017.

${ }^{17}$ Também conhecido pelas alcunhas de Nick Nicotine e Suave, entre outras.

18 Mais em https://support.duplication.cdbaby.com/hc/en-us/articles/205394688-What-is-the-differencebetween-a-CD-and-a-CD-R-. Acessado em 28/03/21.

${ }^{19} \mathrm{O}$ mp3 é a abreviatura para 'Moving Picture Experts Group, Audio Layer III', que foi o método usado pelo grupo de pesquisa liderado pelo engenheiro alemão Karlheinz Brandenburg em pesquisas Sobre áudio na Universidade de Erlangen, Alemanha (WITT, 2015).
} 
(quando acontecia) de fonogramas não seria suficiente para manter o selo. Era preciso que a produção se fizesse conhecida através de concertos e festivais.

O início foi marcado por algumas características comuns a selos do tipo até então, como a falta de planejamento e o desejo de disseminar a música feita no território que não teria espaço em grandes gravadoras. As primeiras produções da Hey, Pachuco! eram comercializadas inicialmente em lojas de Lisboa, vendidas pelo correio ou no próprio festival e concertos das bandas pelo país. As cópias eram feitas a partir do estúdio pessoal de Carlos Ramos e somente a partir da quarta edição, com dinheiro reservado da venda de outros álbuns (e de investimento pessoal) houve como lançar alguns álbuns em vinil.

Outro aspecto inerente a iniciativas do gênero e que marca a Hey, Pachuco! é uma pequena comunidade que forma em torno delas baseados nos ethos do DIY e do DIT, habilitando pessoas 'comuns' como produtores de cultura. Todos podem participar. Sem funções rigidamente definidas dentro do nicho, todos têm importância na sobrevivência e disseminação das produções destas gravadoras (Guerra, 2018; Martins e Guerra, 2018; McKay, 1998; Oliveira et al, 2016; Stahl, 2011). Como diz Carlos, a Hey, Pachuco! era, e ainda é, uma gangue de pessoas em prol da música (Carlos Ramos, músico, em entrevista pessoal). E, devido a ela, conseguiu superar os anos de forte crise econômica que Portugal viveu na segunda metade da década dos anos 2000.

Segundo Oliveira et al, a Hey, Pachuco! deve ser entendida como "resultado da explosão de possibilidades trazida por um lado pelos princípios do DIY e, por outro, pelas inovações tecnológicas que, como dissemos, democratizaram o acesso às formas de produção musical” (Oliveira et al., 2016:802). Essas iniciativas demonstram a importância de ações em favor de uma cultura musical que esteja à margem do status quo (idem, ibidem). Porém, na Hey, Pachuco! nunca houve grandes condições para a sustentabilidade da gravadora. Não há salários ou vínculos formais. As remunerações são feitas a partir de projeto a projeto e os apoios que cada um recebe ou da verba que gera.

A 'obrigatoriedade' de uma gestão mais compartilhada, $360^{\circ}$, de uma gravadora indie entre edição, festivais e outros se dá, segundo Carlos e outros managers de gravadoras entrevistados para outros trabalhos, ao pequeno mercado fonográfico português. Ter eventos agregados como festivais, feiras, workshops etc. é muitas vezes o que rende dividendos para o selo continuar as atividades de edição.

O nosso mercado é muito pequeno e as pessoas são levadas a fazer de tudo. $\mathrm{Na}$ Espanha, uma banda qualquer consegue fazer shows a 12 euros e ter salas cheias. Em Portugal não há dinheiro. Precisamos aqui é agitar a comunidade 
da melhor maneira possível. Se não há apoios a melhor maneira é agregar as pessoas em torno de iniciativas culturais. (Carlos Ramos, músico, em entrevista pessoal).

A gravadora também confirma o seu papel de chancela, de prescritores de gosto (Gallago Pérez, 2011; Hennion, 2011). Na Hey, Pachuco!, muitas bandas apresentam produções prontas para Carlos e só aspiram que haja o selo da gravadora estampado nos discos. Ou seja, artistas que desejam ter seus nomes vinculados a certos selos pois isso dará imediata identificação com determinados nichos e/ou porque são fãs daquela gravadora e estar sob sua 'chancela' é fator de orgulho. "Isso acontece com alguma frequência, pois sempre houve muito pouco dinheiro envolvido e mesmo sabendo disso, há bandas que querem ter seus nomes ligados a nós" (Carlos Ramos, músico, em entrevista pessoal). Foi o caso, por exemplo, dos barreirenses Conan Castro and the Moonshine Piñatas e do disco Cataplana America, lançado em 2017 pelo selo.

O Conan Castro gravou no nosso estúdio e queria o selo da Hey, Pachuco! no disco. E assim tornou-se um disco da Pachuco. Não havia investimento, um plano de negócios ou de lançamento quando ele gravou conosco. (Carlos Ramos, músico, em entrevista pessoal).

Muito dessa 'rubrica' não se prende a questões somente sonoras ou de gêneros musicais, mas muitas vezes, talvez a maioria dos casos, a tópicos ligados a atitude, postura frente ao mercado fonográfico e cultural. No caso da Hey, Pachuco! houve uma junção de todas. A atitude de ter uma gravadora para promover a música no Barreiro gerou uma comunidade em torno de um gênero específico do rock, uma música conhecida como garage rock ${ }^{20}$, de estruturas simples, barulhenta e que tem raízes no rockabilly americano dos anos 50 e 60 e que reflete diretamente o gosto pessoal de Carlos Ramos e a programação do (finado em 2019) Barreiro Rocks.

Mesmo mais ligada ao garage rock, Carlos Ramos considera que a Hey, Pachuco! não possui uma linha editorial. As bandas que lançam fonogramas com o selo da gravadora são aquelas que por motivos de gosto, de afinidade (Beividas e Farias, 2006; Brandão et al, 2019; Hennion, 2002, 2011) o atraem num primeiro momento.

Tem que fazer sentido. Existe algo nas bandas da Hey, Pachuco! que gerou uma conexão automática não só pelo som, mas por um ethos, uma postura. Algo subjetivo que não sei explicar. Era uma postura que nos identificava como 'Pachuco'. (Carlos Ramos, músico, em entrevista pessoal).

\footnotetext{
${ }^{20}$ Mais em https://www.masterclass.com/articles/garage-rock-music-guide\#a-brief-history-of-garage-rock. Acessado em 25/1072021
} 


\section{O festival e a precariedade do Barreiro}

O Barreiro Rocks foi, durante a sua existência ${ }^{21}$, foi um catalisador deste tipo musical. O festival agregou, durante os 19 anos de existência, bandas mais afeitas ao garage rock ajudando a construir uma cena musical no Barreiro em torno deste gênero, fazendo com que o local fosse imediatamente associado a ele, reconhecido como o grande polo do estilo em Portugal. Ora, uma gravadora indie tem como premissa, além de divulgar a música das suas comunidades num primeiro momento, também de revelar e difundir o gosto pessoal dos seus managers ou notáveis (Guerra, 2010, 2013; Moura, 2021; Moura et al, 2020), são verdadeiros propagadores de determinados tipos de música, de atitudes e de posturas frente ao mainstream, como é o caso de Carlos Ramos. Assim como a gravadora, o festival servia para dar palco para bandas que não tinham espaço e voz em Lisboa, por exemplo. Isto, na visão de Carlos Ramos, ajudou a destacar no Barreiro Rocks a sua função social, para além da música.

A gravadora continua movimentando o território com uma boa oferta de bandas (muitas surgidas pela vontade de tocar no Barreiro Rocks) e pequenos concertos em bares e locais improvisados para driblar a falta de estrutura, e assim, manter um intercâmbio com artistas de outras localidades. "O Barreiro nunca teve muita estrutura para abrigar concertos e bandas. E ficávamos dependentes da zona de bares o que é sempre muito volátil" (Carlos Ramos, músico, em entrevista pessoal). Porém, segundo Carlos Ramos, mesmo a movimentação de bandas após o surgimento da gravadora e do festival não ajudou a fomentar o surgimento de novos locais para a prática musical. Os poucos que ainda existem, são, na maioria, são utilizados pelas atividades da Hey, Pachuco!. De acordo com Carlos, o Barreiro é uma cidade onde ocorrem grandes festivais como o Out Fest $^{22}$ e outros do gênero heavy metal, mas que não possui uma rede de pequenos locais para as novas bandas. "O Barreiro também tem grandes salas que eram usadas para os bailes nos anos 1950 e 1960, enormes, mas que não refletem o que é a produção musical do local hoje" (Carlos Ramos, músico, em entrevista pessoal).

Além disso, o Barreiro Rocks ajudou a colocar Portugal na rota de concertos internacionais devido ao bom relacionamento de Carlos Ramos com bandas estrangeiras,

\footnotetext{
${ }^{21}$ Encerrou as atividades em 2019 devido a impossibilidade de manter as edições com os poucos recursos recebidos da Câmara Municipal local.

22 https://outfest.pt/. Acessado em 26/10/2021.
} 
notadamente espanholas, sendo um festival 'mais ibérico que somente português', fazendo de si um ponto de intercâmbio. O Barreiro Rocks se dizia "como o mais garageiro da ocidental praia lusitana e sublinha a abrangência internacional, que lhe vale sempre a visita de muitos espanhóis melómanos das caves do rock mais roll” (Guerra, 2010: 910).

\section{De selo para associação cultural}

Cenas como as do Barreiro (re)caracterizam o território, (re)configuram-no, mostrando-se ao país e ao mundo como produtores musicais, agregadores sociais e onde a atividade musical impulsionam transformações pessoais, sociais e econômicas. Identidades, relações de amizades, projetos musicais são criados, assim como experiências são compartilhadas. Movimentações desse tipo suplantam, e surgem para tal, a precariedade, o tédio e a falta de perspectivas (tanto culturais como sociais) (Brake, 1980; Stahl, 2011, 2014), fazendo florescer sentimentos de pertença, gostos e afetos (Brandão et al, 2019; Filho, 2004; Grossberg, 2006; Janotti Júnior, 2001, 2004).

Como diz Carlos $\operatorname{Ramos}^{23}$, o meio independente cria públicos, cria relações através de ideias novas e de vanguarda, em contrapartida nichos estabelecem conexões com este tipo de gravadora e suas produções. O trabalho da Hey, Pachuco! ainda é o de mostrar que não havia a necessidade de atravessar o rio para ir a um concerto ou comprar um disco de uma banda. A intenção continua fazer do Barreiro um polo cultural, que pode haver cultura na cidade, mantendo a necessidade de "alimentar a comunidade, de estar com as pessoas" (Carlos Ramos, músico, em entrevista pessoal).

Isto ainda merece maior destaque pois não falamos de uma localidade a quilômetros de uma grande cidade, mas sim de um território que está a poucos minutos de Lisboa, a capital e principal núcleo cultural, social e econômico de Portugal. Logo, é muito comum que o Barreiro seja visto como uma 'cidade dormitório', onde as pessoas têm suas casas, mas trabalham e têm vidas sociais e culturais do outro lado do Rio Tejo. "A vida do barreirense em geral é estudar aqui, depois vai para a faculdade ou trabalhar em Lisboa e faz a vida na capital" (Carlos Ramos, músico, em entrevista pessoal). Além disso, o papel da Hey, Pachuco! em produzir atividades culturais no Barreiro visa também combater uma certa arrogância da capital em relação ao o que acontece na Margem Sul: 
Devido ao nosso intercâmbio, até 2010, em pesquisas informais que fazíamos no Barreiro Rocks, havia mais pessoas da Espanha que da própria capital. Foi preciso um artigo no Público ${ }^{24}$ naquele ano sobre o evento para que em 2011 tivéssemos a percepção que isso estava mudando, com mais lisboetas a visitar o festival. (Carlos Ramos, músico, em entrevista pessoal).

Em um outro movimento que caracteriza as gravadoras do novo século, a Hey, Pachuco! precisou se 'oficializar' para estar apta a receber apoios públicos para manter o trabalho, mais notadamente para o festival. Assim, a gravadora se tornou em 2005 uma associação cultural ("Hey! Pachuco | Associação Cultural”, 2000; Oliveira et al, 2016) por contingências burocráticas e legais e a uma necessidade de formalização da gestão das atividades do selo e para a viabilização de projetos futuros. Com a transformação em associação foi possível a contratação pontual de pessoas para os projetos que surgiam. Desse modo, foi viável explorar e intervir de forma mais ativa no território e ter acordos com o poder público. Esta relação com câmaras municipais ou até o governo federal, seja para apoios, seja em cessão de espaços é outra característica comum dos selos indie portugueses a partir dos anos 2000, como se vê na Lovers \& Lollypops ${ }^{25}$, Omnichord Records $^{26}$, Revolve ${ }^{27}$, ZigurArtists ${ }^{28}$, entre outros (Moura, 2021).

\section{Agregar Jovens Músicos}

Uma das iniciativas mais destacadas a partir deste momento foi a criação do programa Jovens Músicos. Nele, adolescentes do Barreiro ensaiavam de graça nos horários livres do estúdio de Carlos (agora uma sala alugada no centro do Barreiro e não mais no quarto da sua casa) e em contrapartida a Baía do Tejo ${ }^{29}$, empresa de gestão territorial que detém o terreno onde está localizada a sala, na zona industrial, a redução de aluguel. Pela iniciativa, a Hey, Pachuco! recebeu em 2014 da Câmara Municipal do Barreiro a homenagem ‘Barreiro Reconhecido' na área da Cultura, Artes e Letras ${ }^{30}$.

Por ser um gênero que necessita de inovação constante e da atenção ao que acontece a sua volta, selos indie geralmente estão à frente das majors no que se refere a táticas e estratégias de negócios para poderem sobreviver. Criada a partir da plataforma

\footnotetext{
${ }^{24} \mathrm{Um}$ dos maiores jornais de Portugal, com sede em Lisboa. Mais em https://www.publico.pt. Acessado em $22 / 10 / 2021$.

${ }^{25} \mathrm{https}: / / \mathrm{www}$. loversandlollypops.net/

${ }^{26} \mathrm{https}: / /$ omnichordrecords.com/pt/

${ }^{27} \mathrm{http}: / /$ rvlv.net/

${ }^{28} \mathrm{http}: / / \mathrm{www} . z i g u r a r t i s t s . c o m /$

${ }^{29}$ Mais em http://www.baiadotejo.pt/pt. Acessado em 21/10/2021.

${ }^{30} \mathrm{https}: / /$ www.cm-barreiro.pt/. Acessado em 25/10/2021.
} 
Music Factory (para a captação de apoios para projetos de inclusão social com empresas e poder público) da própria Hey, Pachuco! (Oliveira et al, 2016), o programa ajudou a formar uma nova geração de músicos, bandas e demais agentes que gravitam em torno da cena musical do Barreiro. Um deles, Guilherme Firmino, nascido à época da primeira edição do Barreiro Rocks, em 2000, é hoje um dos produtores da Hey, Pachuco!. Guilherme, estudante de design em Lisboa e músico da banda local Humana Taranja ${ }^{31}$, representa a renovação de uma cena, o fomento de uma nova geração que cresceu indo ao Barreiro Rocks e que, segundo Carlos Ramos, têm ajudado na revitalização e na redefinição do que será o selo para os próximos anos, assim como da própria cena musical do Barreiro. O que poderíamos pensar em um aspecto de 'retribuição', uma vez que Guilherme confirma a relação desde cedo com o selo e os eventos da Hey, Pachuco!:

\begin{abstract}
Depois de começarmos a ensaiar no estúdios, fomos aos concertos, ao Barreiro Rocks, conhecer pessoas... A minha adolescência foi toda em torno dos eventos da Hey, Pachuco! no Barreiro. E, por isso, ela tem influência direta na minha atividade hoje como produtor cultural. (Guilherme Firmino, produtor, em entrevista pessoal).
\end{abstract}

\title{
Conclusões
}

A miríade de atividades da Hey, Pachuco!, assim como tantas outras iniciativas do tipo, podem ser vistas de formas mais claras quando as analisando sob os conceitos de cenas musicais e dos mundos da arte. Oliveira et al dizem que:

\begin{abstract}
Os 'novos independentes' que constituem o paradigma deste tipo de atividades e práticas podem ser vistos como freelancers reduzindo a especialização e promovendo e apreendendo competências múltiplas, permitindo-lhes assumir, formal ou informalmente, o papel de músicos, produtores, designers, promotores, gerando contaminação entre diversos subsetores artísticocriativos, e desafiando as fronteiras entre o profissional e o amador em uma esfera social marcada pelo adensamento relacional, onde as tênues fronteiras entre trabalho e lazer também tendem a se confundir e desaparecer. O artistacriador-consumidor, visto aqui como um verdadeiro empresário de si mesmo. (Oliveira et al, 2016: 803).
\end{abstract}

Mesmo sem o intuito inicial de 'ser uma gravadora do Barreiro'32, a Hey, Pachuco! colocou o nome do local num mapa cultural português, ajudando a solidificar a Margem Sul de Lisboa como um dos polos musicais de maior atividade no país. A gravadora é um símbolo do território onde está sediada e se confunde com a cultura

\footnotetext{
${ }^{31}$ https://www.instagram.com/humanataranja/. Acessado em 25/10/2021.

${ }^{32}$ Carlos Ramos em entrevista pessoal.
} 
musical feita há 20 anos no Barreiro. Todo o processo dentro da gravadora é realizado a partir do tempo livre e da disposição dos agentes a volta dela. Como não há remunerações fixas, cada projeto é pensado de forma a poder retribuir o esforço de cada um.

E são os jovens ‘formados’ pelos eventos da Hey, Pachuco e pelo programa Jovens Músicos, criado pelo selo, ao longo dos anos que representam o futuro da gravadora. Os que hoje gravitam em torno da gravadora de alguma forma estão embebidos com o espírito mais profissional que hoje toma as gravadoras indie. Segundo Carlos Ramos ${ }^{33}$, "com a chegada de um pessoal mais novo como o Guilherme estamos tentando ser mais organizados, com planos de edição, promoção e lançamento".

E se o Barreiro há vinte anos, não era a cidade dos festivais "bacanas" (Cardoso, 2021), tornou-se devido ao Barreiro Fest que movimentou a localidade, sendo ponto de encontro anual e que ficou marcado na história da música pop portuguesa com forte influência na difusão internacional da produção musical local com base no intercâmbio com outros países, mais notoriamente, a Espanha.

A pandemia, como foi vivenciado em todos setores culturais pelo mundo, paralisou a Hey, Pachuco!, mas com a gradual reabertura das salas de ensaio e de espetáculos, a gravadora já têm planos para novas empreitadas. Sempre driblando as dificuldades, a precariedade e a falta de estrutura do Barreiro para a prática musical.

Somos amadores no sentido puro do termo. É feito de esforço e prejuízo pessoal em torno de algo que você nem sabe bem para o que é, mas ao longo dos anos consegue alguns trabalhos, vê alguns projetos acontecendo e com o pessoal novo chegando. Queremos ainda mostrar coisas. O prazer continua e está acima de tudo. (Carlos Ramos, músico, em entrevista pessoal).

\footnotetext{
${ }^{33}$ Carlos Ramos em entrevista pessoal.
} 


\section{Referências}

ABREU, Paula. A música entre a arte, a indústria e o mercado. Um estudo sobre a indústria fonográfica em Portugal. 2010.

ADORNO, T. W. Introdução à sociologia da música Doze preleções teóricas. São Paulo: Ed. UNESP, 2011.

ANDERSEN, Mark; JENKINS, Mark. Dance of Days: duas décadas de punk na capital dos EUA. São Paulo: Edições Ideal, 2015.

AZERRAD, Michael. Our Band Could Be Your Life: scenes from the American indieunderground 1981-1991. New York: BackBay Books, 2001.

BECKER, Howard. Art worlds. London: University of California Press, 1982.

BECKER, Howard. Telling about Society. Chicago: The University of Chicago Press, 2007.

BEIVIDAS, Waldir; FARIAS, Iara Rosa. A formação do leitor: considerações sobre a noção de gosto. Revista Intercâmbio LAEL/PUC-SP, v. XV, 2006.

BELCHIOR NUNES, Pedro. Colectivismo, sinergias e valor artístico : o espaço das micro-editoras independentes em Portugal no século XXI. El Oído Pensante, v. 6, n. 2, p. 27-48, 2018.

BENNETT, Andy. Conceptualising the Relationship Between Youth, Music and DIY Careers: A Critical Overview. Cultural Sociology, v. 12, n. 2, p. 140-155, 2018a.

BENNETT, Andy. Consolidating the music scenes perspective. Poetics, v. 32, n. 3-4, p. 223-234, 2004.

BENNETT, Andy. Popular music scenes and aging bodies. Journal of Aging Studies, v. 45, p. 49-53, 1 jun. 2018b.

BENNETT, Andy; PETERSON, Richard A. Music Scenes: Local, Translocal, and Virtual. [S.1: s.n.], 2004.

BOURDIEU, Pierre. As regras da arte. Lisboa: Editorial Presença, 1996.

BOURDIEU, Pierre. The field of cultural production: essays on art and literature. Nova York: Columbia University Press, 1993.

BRAKE, M. The sociology of youth culture and youth subcultures: sex and drugs and rock " $n$ ” roll. Londres: Routledge, 1980.

BRANDÃO, Marcílio Dantas; GUERRA, Paula; SARROUY, Alix Didier. ANTOINE HENNION: música, mediação e amadores. Estudos de Sociologia, v. 2, n. 25, p. 29-49, 2019.

BYRNE, David. Como Funciona A Música. [S.1.]: Amarilys, 2014. 
CARDOSO, Gonçalo. Carlos Ramos (Suave): "Há 20 anos atrás, o Barreiro não era a cidade dos festivais e da música fixe”. . [S.1: s.n.], 2021. Disponível em:

$<$ https://ultimobarco.com/entrevistas/suave/>.

COHEN, Sara. Bubbles, tracks, borders and lines: Mapping music and urban landscape. Journal of the Royal Musical Association, v. 137, n. 1, p. 135-170, 2012a. Disponível em:

$<$ http://proxy.uchicago.edu/login?url=http://search.ebscohost.com/login.aspx?direct=tru $\mathrm{e} \& \mathrm{db}=\mathrm{rih} \& \mathrm{AN}=2012-02692 \&$ site $=$ ehost-live \&scope $=$ site $>$.

COHEN, Sara. Live music and urban landscape : mapping the beat in Liverpool. v. 22, n. 5, p. 587-604, 2012b.

COHEN, Sara. Rock Culture in Liverpool: Popular Music in the Making. 1991.

COHEN, Sara. Rock music in Liverpool. . [S.1: s.n.]. , 2007

COORD.; FARIA, Miguel Figueira De; MENDES, José Amado (Org.). Actas do colóquio internacional Industrialização em Portugal no século XX: o caso do Barreiro. Lisboa: EDIUAL, 2010.

COSTA, António Firmino Da. Sociedade de Bairro. Dinâmicas Sociais da Identidade Cultural. $2^{a}$ Edição ed. Lisboa: Celta Editora, 2008. Disponível em:

$<$ http://scholar.google.com/scholar?hl=en\&btnG=Search\&q=intitle:Sociedade+de+Bairr o\#1\%5Cnhttp://scholar.google.com/scholar?hl=en\&btnG=Search\&q=intitle:Sociedade+ de+bairro\%231>.

COSTA, Pedro; GUERRA, Paula. Cenas musicais, comunidades, identidades e culturas urbanas. CIDADES, Comunidades e Territórios, v. 31, n. 31, p. 123787, 2016.

CRANE, Diane. The production of culture: Media and the urban arts. Newbury Park, CA: SAGE Publications Ltd, 1992.

CROSSLEY, Nick. Networks of sound, style and subversion. The punk and post-punk worlds of Manchester, London, Liverpool and Sheffield, 1975-80. Manchester:

Manchester University Press, 2015.

DALE, Pete. It was easy, it was cheap, so what?: Reconsidering the DIY principle of punk and indie music. Popular Music History, v. 3, n. 2, p. 171-193, 2009.

FILHO, Jorge Luiz Cunha Cardoso. Afeto na análise dos grupamentos musicais. ECOPÓS, v. 7, n. 2, p. 111-119, 2004.

GALLEGO PÉREZ, Juan Ignácio. Novas formas de prescrição musical. In: HERSCHMANN, MICAEL (Org.). . Nas bordas elou fora do mainstream. Novas tendências da Indústria da Música Independente no início do século XXI. São Paulo: Estação das Letras e das Cores, 2011. p. 47-60.

GROSSBERG, Lawrence. Rock , territorialization and power. n. January 2015, p. $37-$ 41, 2006.

GUERRA, PAULA; MOURA, Luiz Alberto. Contributos para a emergência de uma 
juventude sónica: A constituição da cena noise das Caldas da Rainha. CIDADES , Comunidades e Territórios, v. 32, p. 158-179, 2016.

GUERRA, Paula. ' Just can' $t$ go to sleep ': DIY cultures and alternative economies from the perspective of social theory. Portuguese Journal of Social Science, v. 16, n. 3 , p. 283-303, 2017.

GUERRA, Paula. A instável leveza do rock. Génese, dinâmica e consolidação do rock alternativo em Portugal (1980-2010). Tese de Doutoramento. 2010. Universidade do Porto, 2010. Disponível em:

$<$ http://repositorioaberto.up.pt/handle/10216/56304?mode=full>.

GUERRA, Paula. A Instável Leveza do Rock. Génese, dinâmica e consolidação do rock alternativo em Portugal (1980-2010). Porto: Edições Afrontamento, 2013.

GUERRA, Paula. Nothing is forever : um ensaio sobre as artes urbanas de Miguel Januário. v. 102, p. 19-49, 2019.

GUERRA, Paula. Raw Power: Punk, DIY and Underground Cultures as Spaces of Resistance in Contemporary Portugal. Cultural Sociology, v. 12, n. 2, p. 241-259, 2018.

HEBDIGE, Dick. Subcultura. O significado do estilo. Lisboa: Maldoror, 2018.

HENNION, Antoine. Music and Mediation: Towards a new Sociology of Music. In: CLAYTON, MATIN, ET AL (Org.). . The Cultural Study of Music: A Critical Introduction. London: Routledge, 2002. p. 80-91.

HENNION, Antoine. Pragmatica do Gosto. Desigualdade \& Diversidade - Revista de Ciências Sociais da PUC-Rio, v. 8, p. 253-277, 2011.

HESMONDHALGH, David. Independent record companies and democratisation in the popular music industry. 1996. University of London, 1996.

HESMONDHALGH, David. Post-Punk's attempt to democratise the music industry the success and failure of Rough Trade. Popular Music, v. 16, p. 255-274, 1998.

Hey! Pachuco| Associação Cultural. Disponível em: <http://heypachuco.pt/>. Acesso em: 25 out. 2021.

HIBBETT, Ryan. What is indie rock? Popular Music and Society, v. 28, n. 1, p. 55-77, 2005.

JANOTTI JÚNIOR, Jeder. Afeto, Autenticidade e Socialidade : X Encontro Anual da Associação de Programas de Pós-Graduação em Comunicação, 2001, Brasília. Compós, v. 10, p. 11-26, 2001.

JANOTTI JÚNIOR, Jeder. Gêneros Musicais, performance, afeto e ritmo: uma proposta de análise midiática da música popular massiva. Revista de Comunicação e Cultura, v. 2, n. 2, p. 189-204, 2004. Disponível em: <https://portalseer.ufba.br/index.php/contemporaneaposcom/article/view/3418>.

JANOTTI JÚNIOR, Jeder; PIRES, Victor De Almeida Nobre. Limites das Cidades 
Musicais: problematizando cidade, território e música. In: C.S.M., FERNANDES; HERSCHMANN, MICAEL (Org.). . Cidades musicais: Comunicação, territorialidade e política. Porto Alegre: Editora Sulina, 2018. p. 141-162.

KING, Richard. How Soon is Now - The madmen and mavericks who made independent music 1975-2005. London: Farber \& Farber, 2012.

KRUEGER, Alan B. Rockonomics. O que a indústria da música nos pode dizer ensinar sobre a economia e sobre a vida. $1^{\mathrm{a}}$ ed. Lisboa: Temas e Debates, 2019.

KRUSE, Holly. Local identity and independent music scenes, online and off. Popular Music and Society, v. 33, n. 5, p. 625-639, 2010.

KRUSE, Holly. Subcultural Identity in Alternative Music Culture. Popular Music, v. 12, n. 1, p. 31-43, 1993.

LEGATES, R. T; STOUT, F. The city reader. 6th. ed. London: Routledge, 2011.

MAFFESOLI, Michel. Homo Eroticus: comunhões emocionais. Rio de Janeiro: Forense, 2014.

MAFFESOLI, Michel. O Tempo das Tribos : O declinio do individualismo nas sociedades de massa. $2^{\text {a }}$ Edição ed. Rio de Janeiro: Forense Universitária, 1998.

MARTINS, Ana; GUERRA, Paula. Martins, Ana; Guerra, Paula (2018) O Rock chegou à cidade. As transformações na noite Lisboeta da década de 80.pdf. Convergências Revista de Investigação e Ensino das Artes, v. XI, n. 22, 2018. Disponível em: $\langle\mathrm{http}: / /$ convergencias.ipcb.pt $>$.

MARTINS, Moises de Lemos. A significação e a sua gênese social. 1997.

MARTINS, Moises de Lemos. Semiótica. . Braga: [s.n.], 2004.

MCKAY, George. DiY culture: Towards an intro. DiY culture: Party and protest in nineties Britain, p. 1-53, 1998.

MORAIS, Eduardo. Barreiro Rocks. . Portugal: [s.n.]. Disponível em: <https://www.youtube.com/watch?v=QUQquiud-VY>., 2015

MOURA, Luiz Alberto. (Anti)Tédio Boys O papel das gravadoras indie na cartografia musical portuguesa. Os casos de Coimbra, Porto, Guimarães e Leiria. CSOnline. Revista Eletrônica de Ciências Sociais, n. 33, p. 137-170, 2021. Disponível em: <https://dx.doi.org/10.34019/1981-2140.2021.34174>.

MOURA, Luiz Alberto; RABOT, Jean Martin; MARTINS, Moises de Lemos. Uma Genealogia das Gravadoras Indie em Portugal (1982 - 2017). In Z. Pinto-Coelho; T. Ruão \& S. Marinho (Eds.). Dinâmicas comunicativas e transformações sociais. Atas das VII Jornadas Doutorais em Comunicação \& Estudos Culturais, 2020.

MURPHY, Gareth. Cowboys and indies. The epic history of the record industry. Londres: The Serpent Tail, 2015. 
NOVAK, Franciele Isabelita Lopes; BRANDT, Celia Finck. A semiótica de Peirce e Saussure, contributos e limites para a teoria das representações semióticas de Raymond Duval e a análise da forma e conteúdo em matemática. Revemat: Revista Eletrônica de Educação Matemática, v. 12, n. 2, p. 1-15, 2018.

OGG, Alex. Independence Days: The Story Of UK Independent Record Labels. London: Cherry Red Books, 2009.

OLIVEIRA, Ana; COSTA, Pedro; GUERRA, Paula. Território(s) e territorialidade(s) das cenas musicais alternativas lisboetas: uma aproximação através de alguns Iugares de referência. In: GUERRA, PAULA (Org.). . More than loud: os mundos dentro de cada som. Porto: Afrontamento, 2015. p. 187-202.

OLIVEIRA, Ana; GUERRA, Paula; COSTA, Pedro. Reviving DIY: The importance of Do It Yourself to the Portuguese alternative rock scene. What's Ahead in Service Research, p. 789-806, 2016.

REYNOLDS, Simon. Totally Wired: postpunk interviews and overviews. Berkeley: Soft Skull Press, 2009.

SANTAELLA, Lucia. O que é semiótica. São Paulo: Brasiliense, 1995.

SHANK, Barry. Dissonant Identities: The Rock 'n' Roll Scene in Austin, Texas. Hanover, N.H.: University Press of New England, 1994.

STAHL, Geoff. DIY or DIT Tales of Making Music in a Creative Capital. In: MITCHELL, GLENDA KEAM AND TONY (Org.). . Home, Land and Sea: Situating Music in Aotearoa New Zealand. Auckland: Pearson, 2011. p. 145-160.

STAHL, Geoff. Poor, but sexy Reflections on Berlin scenes. p. 7-20, 2014.

STRAW, Will. Systems of Articulation, Logics of Change: Communities and Scenes in Popular Music. Cultural Studies, v. 53, p. 368-388, 1991.

TARASSI, Silvia María. Independent to What? An Analysis of The Live Music Scene in Milan. p. 1-280, 2011.

ULUSOY, Emre. Subcultural escapades via music consumption: Identity transformations and extraordinary experiences in Dionysian music subcultures. Journal of Business Research, 2016.

WITT, Stephen. Como a Música Ficou Grátis. [S.1.]: Intrinseca, 2015.

Data de submissão: 15 de julho de 2020

Data de publicação: 20 de dezembro de 2021 